\title{
Downscaling extreme month-long anomalies in southern South America
}

\author{
C. G. Menéndez • M. de Castro • J.-P. Boulanger • A. D'Onofrio • E. Sanchez • \\ A. A. Sörensson • J. Blazquez • A. Elizalde • D. Jacob • H. Le Treut • Z. X. Li • \\ M. N. Núñez • N. Pessacg • S. Pfeiffer • M. Rojas • A. Rolla • P. Samuelsson • \\ S. A. Solman · C. Teichmann
}

Received: 23 June 2008 / Accepted: 3 August 2009 / Published online: 17 October 2009

(C) The Author(s) 2009. This article is published with open access at Springerlink.com

\begin{abstract}
We investigate the performance of one stretched-grid atmospheric global model, five different regional climate models and a statistical downscaling technique in simulating 3 months (January 1971, November 1986, July 1996) characterized by anomalous climate conditions in the southern La Plata Basin. Models were driven by reanalysis (ERA-40). The analysis has emphasized on the simulation of the precipitation over land and has provided a quantification of the biases of and
\end{abstract}

C. G. Menéndez $(\varangle)$ · A. A. Sörensson · J. Blazquez · M. N. Núñez · N. Pessacg ·

A. Rolla · S. A. Solman

Centro de Investigaciones del Mar y la Atmósfera, CONICET-UBA, Pabellón 2, Piso 2,

Ciudad Universitaria, 1428 Buenos Aires, Argentina

e-mail: menendez@cima.fcen.uba.ar

M. de Castro $\cdot$ E. Sanchez · A. Elizalde

Facultad de Ciencias del Medio Ambiente, Universidad de Castilla-La Mancha, Toledo, Spain

J.-P. Boulanger

Laboratoire d'Océanographie et du Climat, UMR CNRS/IRD/UPMC, Paris, France

A. D’Onofrio

DC, FCEN, Universidad de Buenos Aires, Buenos Aires, Argentina

C. G. Menéndez · S. A. Solman

DCAO, FCEN, Universidad de Buenos Aires, Buenos Aires, Argentina

A. Elizalde · D. Jacob · S. Pfeiffer · C. Teichmann

Max Planck Institute for Meteorology, Hamburg, Germany

H. Le Treut · Z. X. Li

Laboratoire de Météorologie Dynamique, CNRS, Paris, France

M. Rojas

Departamento de Geofísica, Universidad de Chile, Santiago, Chile

P. Samuelsson

Rossby Centre, SMHI, Norrköping, Sweden 
scatter between the different regional simulations. Most but not all dynamical models underpredict precipitation amounts in south eastern South America during the three periods. Results suggest that models have regime dependence, performing better for some conditions than others. The models' ensemble and the statistical technique succeed in reproducing the overall observed frequency of daily precipitation for all periods. But most models tend to underestimate the frequency of dry days and overestimate the amount of light rainfall days. The number of events with strong or heavy precipitation tends to be under simulated by the models.

\section{Introduction}

Global climate models (GCMs) cannot provide information at scales finer than their grid (nowadays typically in the range from 125 to $400 \mathrm{~km}$ ). However, as the needs of the impact community are a local- and regional-scale problem and, at the same time, the physical processes at the scales unresolved by GCMs are important, there is a growing motivation for downscaling the simulations provided by global models. Downscaling can be carried out through different techniques. Refining part of the grid of a GCM (variable-resolution global models) or using high resolution Regional Climate Models (RCMs) nested in GCMs improves the spatial details of the simulated climate. Similarly, statistical downscaling of GCM simulations provides enhanced performance for many applications.

CLARIS has promoted the coordinated participation of European and South American research teams in the use, development and application of downscaling (dynamical and statistical) methods. Different kinds of activities were executed including coordinated experiments for dynamical downscaling and complementary research activities performed by individual partners (e.g. statistical downscaling studies). Dynamical downscaling can generate realistic regional climate information that is consistent with the driving large-scale atmospheric circulation. Nevertheless, there are uncertainties, such as systematic biases in the RCMs and the propagation of errors from the driving data to the inner regional domain.

At the starting point of the project (year 2005) there was little experience in the use and development of RCMs and downscaling techniques for most of the South American regions. Even at present much of the work on this issue in South America remains at the level of methodological development and preliminary testing. Nevertheless, downscaled multi-year simulations and climate change projections are starting to become available for this region and a great part of the effort is being channelled within the CLARIS framework. Multi-year simulations were recently accomplished and first results are being independently analysed by the different groups within the project (e.g. Solman et al. 2007; Menéndez et al. 2007). A collaborative research for studying the regional climate as simulated by the ensemble of CLARIS models is in progress. Concurrently, RCMs are being applied to study regional effects of global climate change in South America (Núñez et al. 2006; Marengo 2007; Fuenzalida 2007; Sörensson et al. 2007) and other regions. A comprehensive recent review on regional climate modelling and downscaling techniques can be found in the Fourth Assessment Report of the International Panel on Climate Change (Christensen et al. 2007). Other recent articles on South 
American regional simulation include Rauscher et al. $(2006,2007)$ and Seth et al. (2007).

Many impacts of climate change are related to changes in frequency or intensity of extremes. The understanding of downscaling skill for extreme periods is currently uncertain, yet presumably of greater importance than downscaling small changes in the mean. In particular, downscaling extreme episodes in the monthly to seasonal scale is a challenging issue. Nonetheless, relatively little has been done for downscaling the intraseasonal scale in South America (e.g. Misra et al. 2003).

The aim of this paper is to provide preliminary insight on some of the downscaling issues relevant to CLARIS scientific objectives. We describe the results of the first coordinated exercise performed in the CLARIS framework: a series of regional simulations performed with six models driven by reanalysis (ERA-40) as an endeavour to assess models' behaviour in particular month-long extreme cases. The analysis concentrates mainly on precipitation in the southern La Plata Basin. A statistical downscaling system (SDS; D'Onofrio et al. 2009) is also tested for downscaling precipitation over eastern Argentina from ERA40. Descriptions of the experimental design and of the three anomalous selected periods are given in Sections 2 and 3, while the analysis of ensemble performances and statistical downscaling is presented in Section 4 and final remarks are presented in Section 5.

\section{Models and techniques}

We carried out three multi-model ensembles of simulations of particularly anomalous months in terms of precipitation in the southern La Plata Basin (January 1971, November 1986 and July 1996). RCMs participating in this coordinated dynamical downscaling experiment include the following: MM5 (CIMA and UCH), RCA3 (CIMA and Rossby Centre/SMHI), REMO (MPI-M), PROMES (UCLM) and WRF (CIMA). LMDZ (LMD), an atmospheric GCM with stretched grid, also participates in these experiments. A short description of participating models is given in Table 1. In order to reduce the spread in the multi-model ensemble, a coordinated approach in terms of model domain and resolution, time periods and models' forcing for all simulations was established. This experiment design allows the identification of features that are common or vary across the ensemble of models. The selection of the periods is based on in situ observational data studies for central and north-eastern Argentina (Bettolli et al. 2005; Barrucand and Rusticucci 2001).

The SDS method used in the present study was based on the classification of weather patterns (see D'Onofrio et al. 2009 for a detailed description of the method). Briefly, daily weather patterns (based on 17 variables) are classified to a reduced space of 196 clusters. Ensembles of 100 stochastic simulations are then realized to evaluate the statistical model skills. This method has been tested and applied to stations covering a variety of Argentinean climates. In the present paper it is focused on the regions of major amplitude of the observed extreme events.

All dynamical regional simulations were initialized and forced every $6 \mathrm{~h}$ by largescale atmospheric boundary conditions from the European Centre for MediumRange Weather Forecasts (ECMWF) 40-year Reanalysis (ERA-40, Uppala et al. 2005). The stretched-grid global model LMDZ was used in a nudged mode, where forcing variables are relaxed towards the driving data (ERA-40) in the global grid 


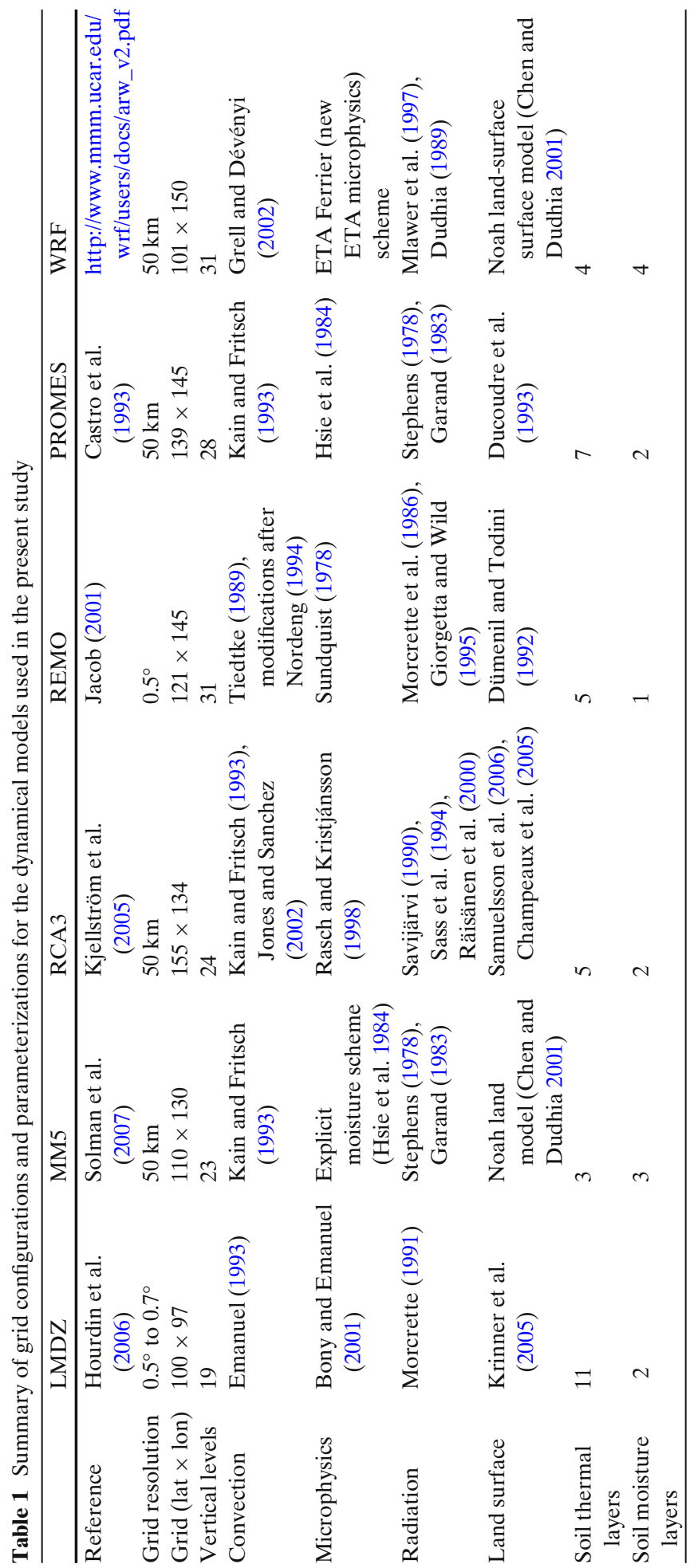


outside South America. All models were run with horizontal resolution of about $50 \mathrm{~km}$ over South America but varying vertical resolution. The five regional models' domains are somewhat different from model to model but share southern South America and surrounding oceans.

Each simulation considers a spin up period of about 30 days, i.e. length of simulations is 2 months, but only the last simulated months-January 1971, November 1986 and July 1996-were analyzed. A spin up period of 1 month may be sufficient for the atmospheric and upper soil layer, but it is not enough for deep soil layer variables (Christensen 1999). Therefore, a word of caution should be given regarding our results as the simulations may be influenced by this lack of equilibrium (however, the shortness of our simulations may substantially reduce the influence of the slowly evolving deeper soil layers). Several studies have investigated the time it takes a model to achieve thermal and hydrologic equilibrium with the atmospheric forcing. According to Giorgi and Mearns (1999) the top soil layer ( $\sim 10 \mathrm{~cm}$ depth) equilibrates with the overlying climate relatively quickly (order of a few weeks), while for a root zone of $1 \mathrm{~m}$ depth the equilibration time may be of several seasons and for a deeper soil, it may be of several years. A great disparity in spin up time between models, variables and regions is often reported. Important reductions in spin up time are expected in humid regions (Rodell et al. 2005) and, in particular, subtropical South America is a region where a quick equilibrium is expected (Silva and Berbery 2006). In addition, the soil moisture initialization from reanalysis data is more effective than

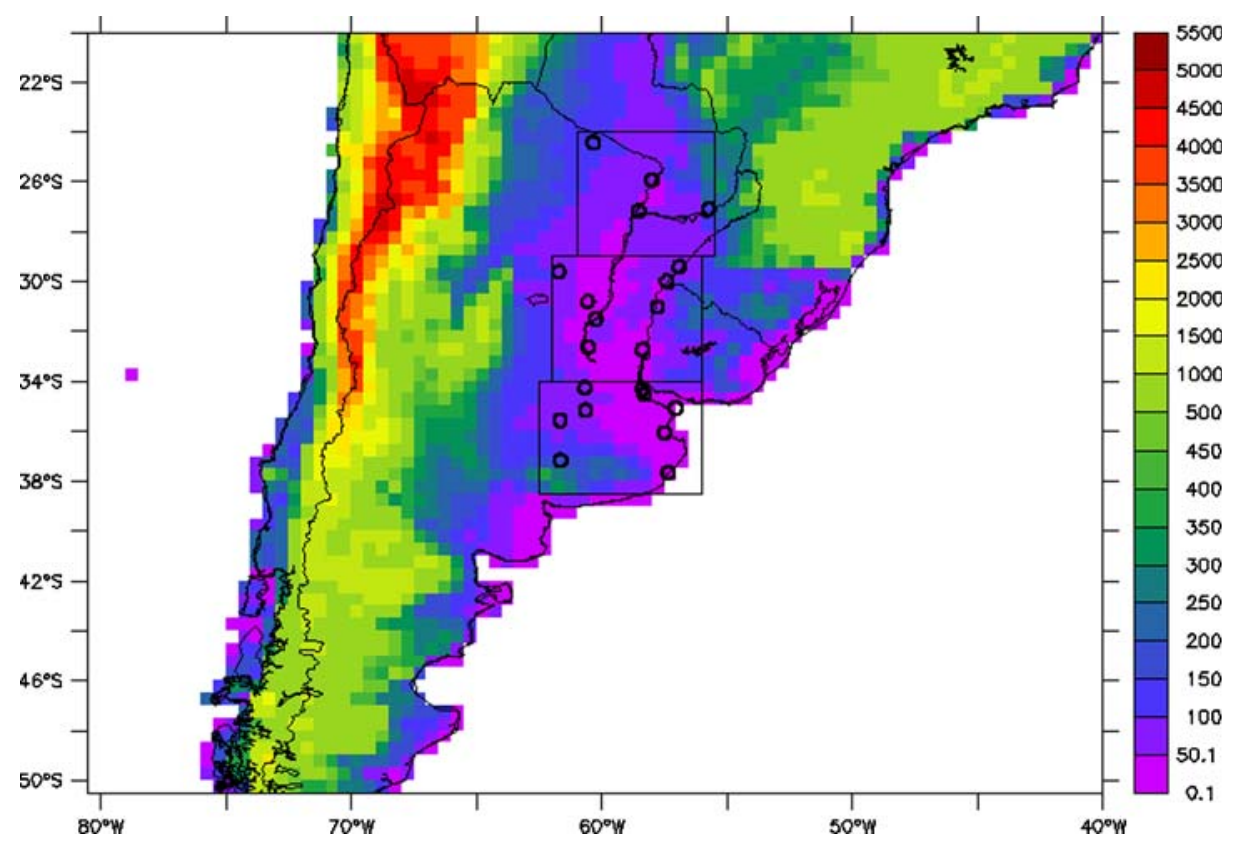

Fig. 1 Regional domain showing the topographic field, the three subregions used to compute statistical measures, and the location of meteorological stations used for comparison with models results 
a dry or wet initialization, significantly reducing the spin up period (Cosgrove et al. 2003).

Simulations were evaluated against both station data and high-resolution $\left(0.5^{\circ}\right)$ precipitation data compiled, respectively, by the CLARIS Work Package 3.2 and the Climatic Research Unit (CRU) of the University of East Anglia (New et al. 1999, 2000). The station dataset consists of daily values of precipitation and mean surface temperature for 38 Argentine weather stations north of $39^{\circ} \mathrm{S}$.

The results are presented for southern South America $\left(50^{\circ} \mathrm{S}, 20^{\circ} \mathrm{S}, 85^{\circ} \mathrm{W}, 35^{\circ}\right.$ $\mathrm{W})$ and for three smaller regions of particular interest for this project in central and north-eastern Argentina that we refer to as North-Eastern Argentina (NEA, $24^{\circ} \mathrm{S}$, $29^{\circ} \mathrm{S}, 55.5^{\circ} \mathrm{W}, 61^{\circ} \mathrm{W}$ ), Southern Mesopotamia (SME, $29^{\circ} \mathrm{S}, 34^{\circ} \mathrm{S}, 56^{\circ} \mathrm{W}, 62^{\circ} \mathrm{W}$ ) and Central-Eastern Argentina $\left(\mathrm{CEA}, 34^{\circ} \mathrm{S}, 38.5^{\circ} \mathrm{S}, 56^{\circ} \mathrm{W}, 62.5^{\circ} \mathrm{W}\right)$. These regions and the observational stations that are used for comparison with model results are presented in Fig. 1. Note that all considered stations are located over relatively flat and low terrain.

\section{Periods description}

Composites of observed circulation anomalies during the 3 months are presented in Figs. 2, 3 and 4, including patterns of geopotential height at $500 \mathrm{hPa}$, wind at $850 \mathrm{hPa}$, surface air temperature and precipitation. The pattern of circulation anomalies during January 1971 (Fig. 2) is very similar to that discussed by Diaz and Aceituno (2003) during episodes of enhanced convection over Uruguay in summer. In particular, the dipolar structure in the precipitation anomaly pattern, with aboveaverage precipitation over southern and central La Plata Basin and a weakened South Atlantic Convergence Zone (SACZ, Kodama 1993) is connected with a large warm-core anticyclonic circulation anomaly centred between both regions. This anticyclonic circulation anomaly favours an intensified advection of warm and humid air toward south-eastern South America from the Amazon basin. Consistently, the low-level jet (LLJ, a regional intensification of a continental-scale gyre channelled along the eastern foothills of the Andes into northern Argentina and Paraguay, e.g. Marengo et al. 2004) was particularly strong during this month. At midlatitudes, a negative height anomaly centred eastward of Patagonia is coherent with the wavelike quasi-barotropic structure described by Diaz and Aceituno (2003). The temperature anomaly field with large cold anomalies southward of $30^{\circ} \mathrm{S}$ suggests an enhanced subtropical-extratropical baroclinicity over the continent. This negative anomaly of temperature in southern South America is associated with anomalously strong southwesterlies over Patagonia and southerlies in central Argentina.

November 1986 was another month of enhanced precipitation in the Rio de la Plata area (Fig. 3). The low-level flow is a key feature in the development of precipitation in this region (Silva and Berbery 2006). In this respect, the anomalous circulation patterns relative to January 1971 and November 1986 roughly show some similar features. A positive quasi-barotropic geopotential height anomaly eastward from Uruguay goes along with an anticyclonic circulation anomaly over the eastern portion of subtropical South America throughout the troposphere. In contrast, 
a

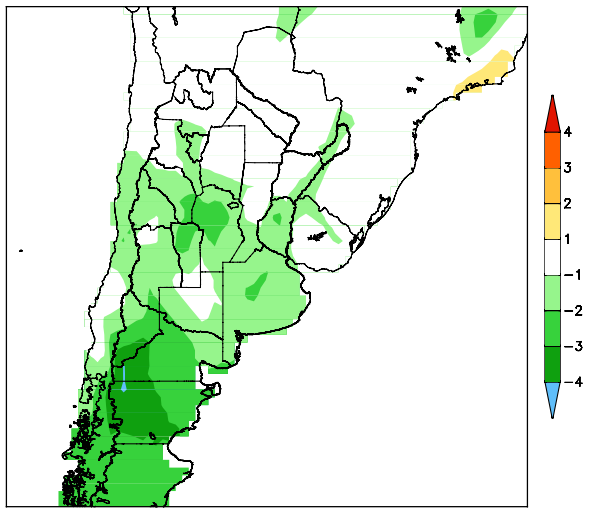

c

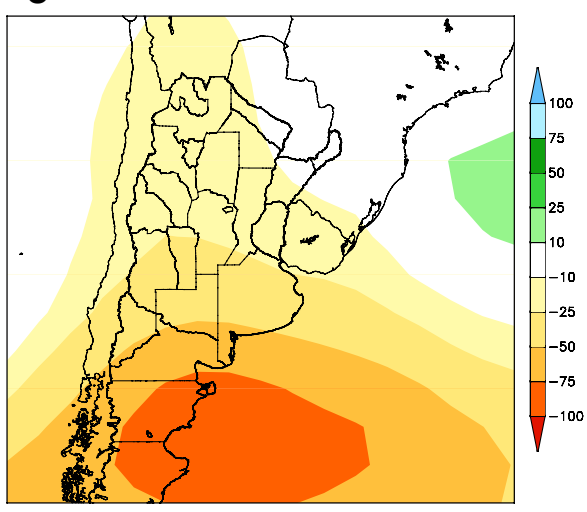

b

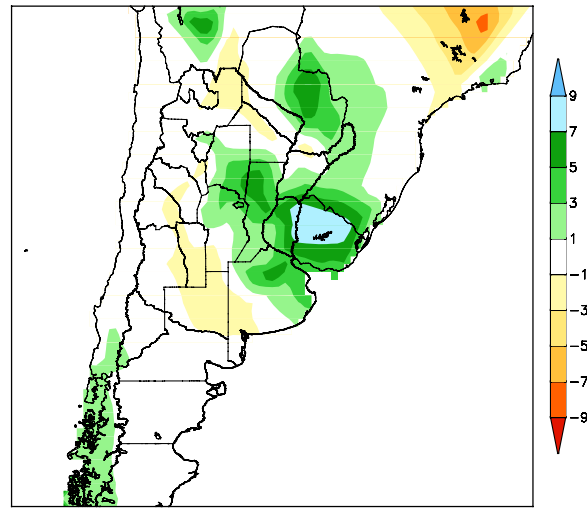

d

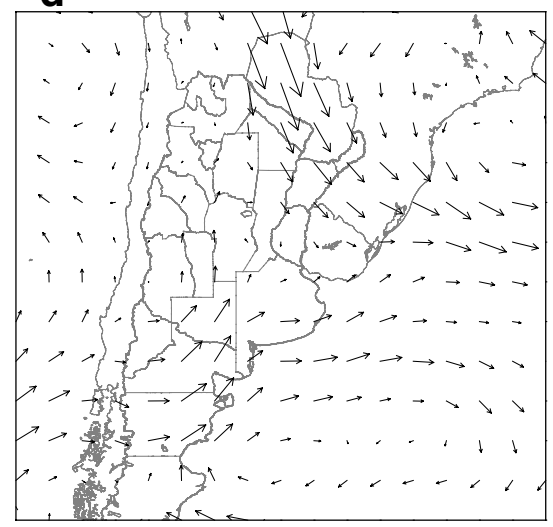

$\longrightarrow$

Fig. 2 CRU-anomalies of a 2-m temperature, in degree Celsius, and $\mathbf{b}$ precipitation, in millimeter per day; and ERA-40 anomalies of $\mathbf{c} 500 \mathrm{hPa}$ geopotential, in meter, and d $850 \mathrm{hPa}$ wind, in meter per second, for January 1971. Reference period for the anomalies: 1961-2000

negative height anomalies centred near $50^{\circ} \mathrm{S}$ sustain a cyclonic vortex in the anomaly wind field around this region. This pattern of circulation anomalies also resembles the wavelike quasi-barotropic structure discussed by Diaz and Aceituno (2003) for episodes of enhanced convection in the Rio de la Plata region during spring, but the wave-train depicted in that paper is located about $5^{\circ}$ to $10^{\circ}$ further to the north. Near the surface, the relatively warm conditions over southern Brazil favoured by the intensified north easterly flow, and the cold anomalies over a large portion of central Argentina and northern Patagonia, suggest an enhanced baroclinicity over the region. Notice that the anomalous winds toward north-eastern Argentina and Uruguay are not limited to the LLJ, but rather inflow is also apparent directly from southern Brazil. 
a

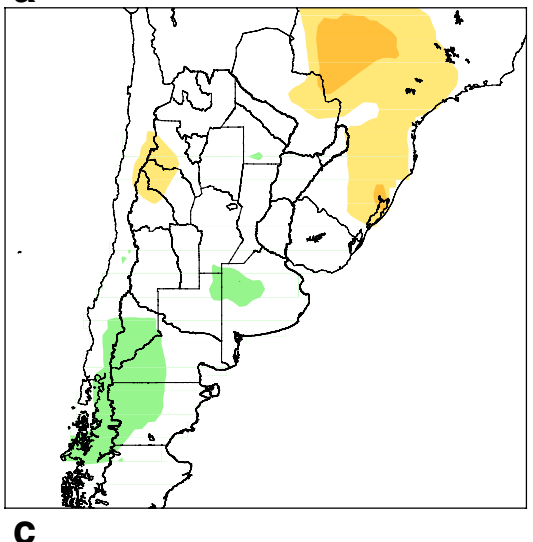

C

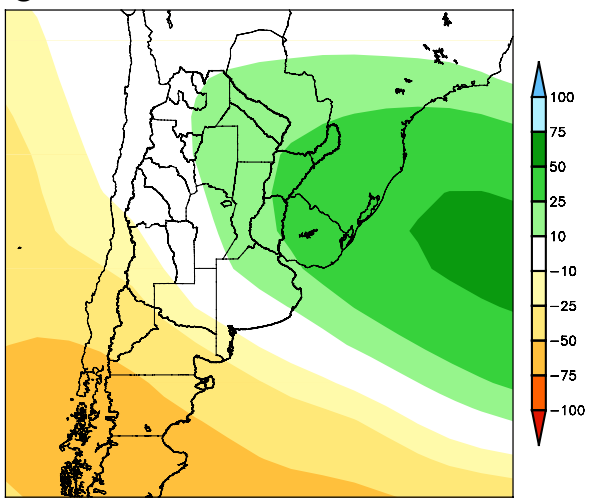

b

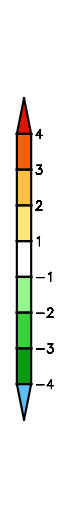

d

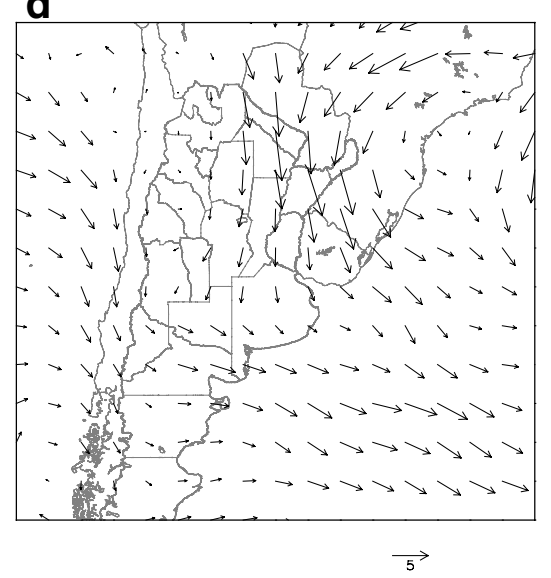

Fig. 3 a-d As Fig. 2, but for November 1986

July 1996 was anomalously dry and cold in the southern La Plata Basin (Fig. 4). According to Hoskins and Hodges (2005), who discuss SH storm-tracks diagnostics derived from the whole ERA-40 period, the middle- and upper-tropospheric cyclonic features on the subtropical jet impinging on the Andes lead to the generation of lower-tropospheric cyclones in its lee near central and northern Argentina. A contributing factor to the genesis and growth of storms in this region is the moisture convergence associated with the northerly transport by the LLJ. However, during July 1996 anticyclone conditions prevail in the mid-latitudes and anomalous southerlies in the region of the LLJ and southern Brazil characterized the subtropical area. Consistently, this period was drier than usual over both south eastern South America and southern Andes. Positive height anomalies suggesting ridging and blocking centred in southern Patagonia and a cyclonic circulation anomaly over the Atlantic centred at $33^{\circ} \mathrm{S}$ induce strong southerlies over south eastern South America 
a

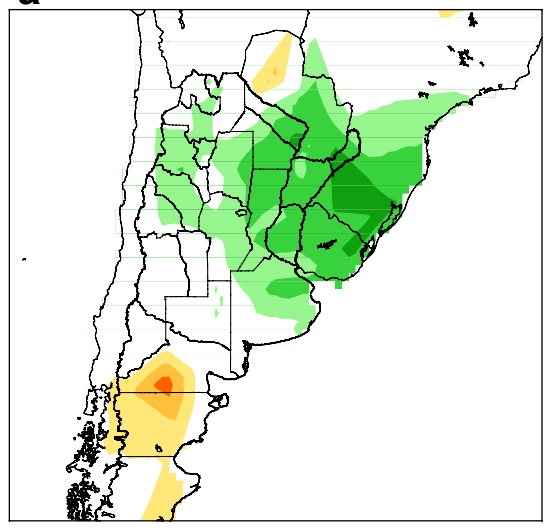

C

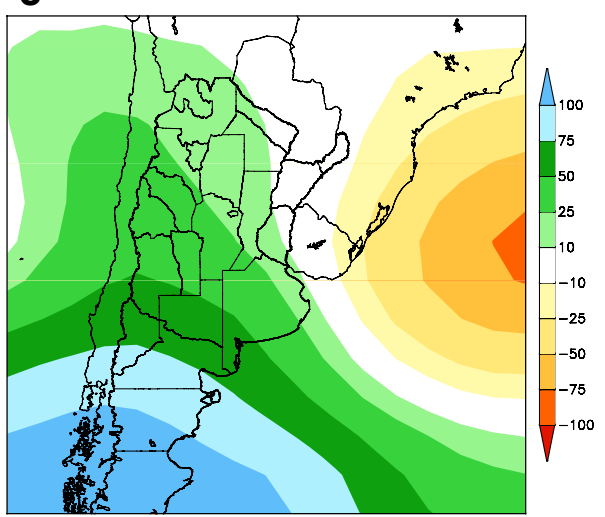

b

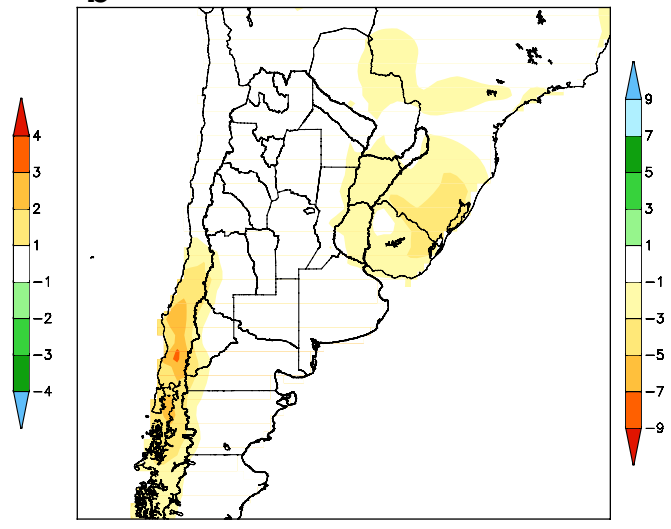

d

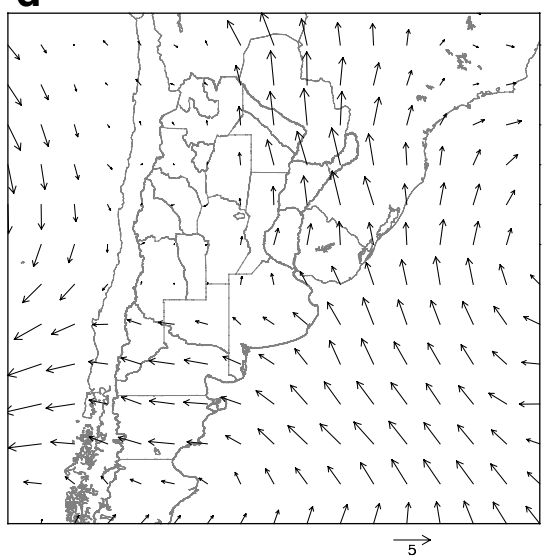

Fig. 4 a-d As Fig. 2, but for July 1996

and consequently relatively severe cold conditions. On the contrary, over Patagonia temperature anomalies are positive since the westerlies are relatively weak.

\section{Results}

\subsection{Monthly mean temperature}

Spatial patterns of the biases of surface air temperature for each of the 3 months as simulated by the models' ensemble with respect to the reference dataset (CRU) are shown in Fig. 5. Additionally, uncertainty ranges were derived based on the found differences between the highest value of the ensemble minus the lowest value at each grid point (intermodel range of monthly mean $2 \mathrm{~m}$ temperature). January 1971 and November 1986 show a quite similar behaviour. During both periods, the ensemble 
JAN 71
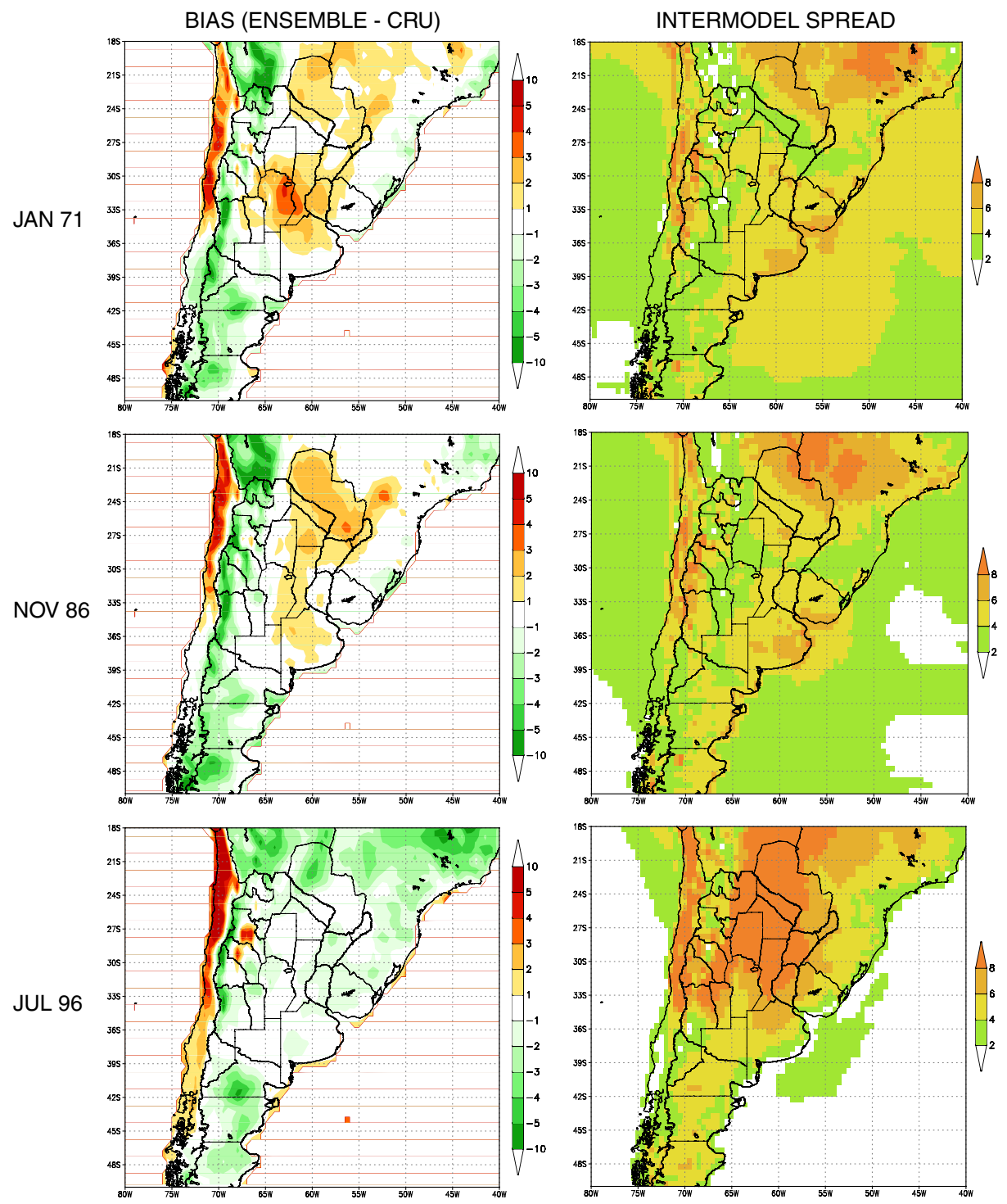

Fig. 5 Biases in monthly mean surface air temperature for the models ensemble for January 1971, November 1986 and July 1996. The simulated temperatures are compared with the CRU data set (left panels). Intermodel range of monthly mean air temperature (right panels). Units: degree Celsius

mean overestimates temperature over large areas in the central and northern part of the domain with a maximum bias of about $+3^{\circ} \mathrm{C}$. The span between models' results is largest over some areas of Brazil (approx. $8^{\circ} \mathrm{C}$ ). The large intermodel spread is mainly caused by too high simulated temperatures in some models during the warm season which are likely connected to a pronounced drying phenomenon (see below). 
This could be a manifestation of an unrealistic partitioning of surface energy into latent and sensible heat fluxes (dry soils limit the energy used to convert water from liquid to gas (i.e., evaporative cooling), so that the ground and then the adjacent air become warmer). Over the southern La Plata basin the ensemble errors and the uncertainty range are relatively smaller. However, a too large intermodel spread (of up to $6-8^{\circ} \mathrm{C}$ ) is still found along the coasts of the Rio de la Plata. For the sake of comparison, the intermodel spread in the southern La Plata Basin monthly mean temperature tends to be similar or larger than the observed interannual spread for each single month. The warm bias diminishes towards the South, being reversed over Patagonia where temperatures tend to be underestimated. The ensemble mean exhibits a quite good behaviour in July 1996, with a negative bias in most areas (the ensemble bias does not in general exceed $2^{\circ} \mathrm{C}$ ). Interestingly, the spread between models results is larger during this wintertime case over most parts of northern Argentina, Paraguay and Bolivia, exceeding $8^{\circ} \mathrm{C}$. Consequently, the relatively good performance of the ensemble-mean in that region results from the averaging of models with quite high biases of opposite sign. A warm bias in Northern Chile and a cold bias along the eastern slope of the Andes Cordillera are systematically found in the 3 months.

\subsection{Monthly mean precipitation}

In January 1971, CRU data shows a precipitation maximum over Uruguay (not shown), which the ensemble locates over southeast Brazil (see the ensemble mean precipitation and the per cent biases in Fig. 6). Most individual models underestimate the mean precipitation over large areas of south eastern South America, with substantial errors in amplitude and location. In November 1986, models capture the maximum over Uruguay and south eastern Brazil, although with different strength, but tend to underestimate precipitation amounts over central and eastern Brazil. In both months, rainfall along the Andes and over Patagonia seems excessive in the ensemble mean. The underestimation of the precipitation amounts in the subtropical plains is also present during July 1996. Even though this winter month was anomalously dry according to the reference observational data set, CRU data shows rainfall of 1-4 mm/day over parts of Uruguay and around the NEA region that are underestimated by all models.

In general, models with positive bias over the Brazilian Altiplano and enhanced SACZ over the Atlantic Ocean during the warm season tend to exacerbate the negative bias over parts of La Plata Basin, and vice versa. This dipole structure in the errors of the simulated precipitation, already hypothesized in Menéndez et al. (2004), is reminiscent of the observed out-of-phase relationship between the precipitation over La Plata Basin and the SACZ region (i.e. the errors of the simulated precipitation may be associated with an incorrect simulation of the amplitude or phase of the dipole variation). This is the main mode of variability for La Plata Basin's summer precipitation and has been found in several studies at intraseasonal to interannual time scales (e.g. Nogués-Paegle and Mo 1997; Liebmann et al. 2004; Boulanger et al. 2005). 

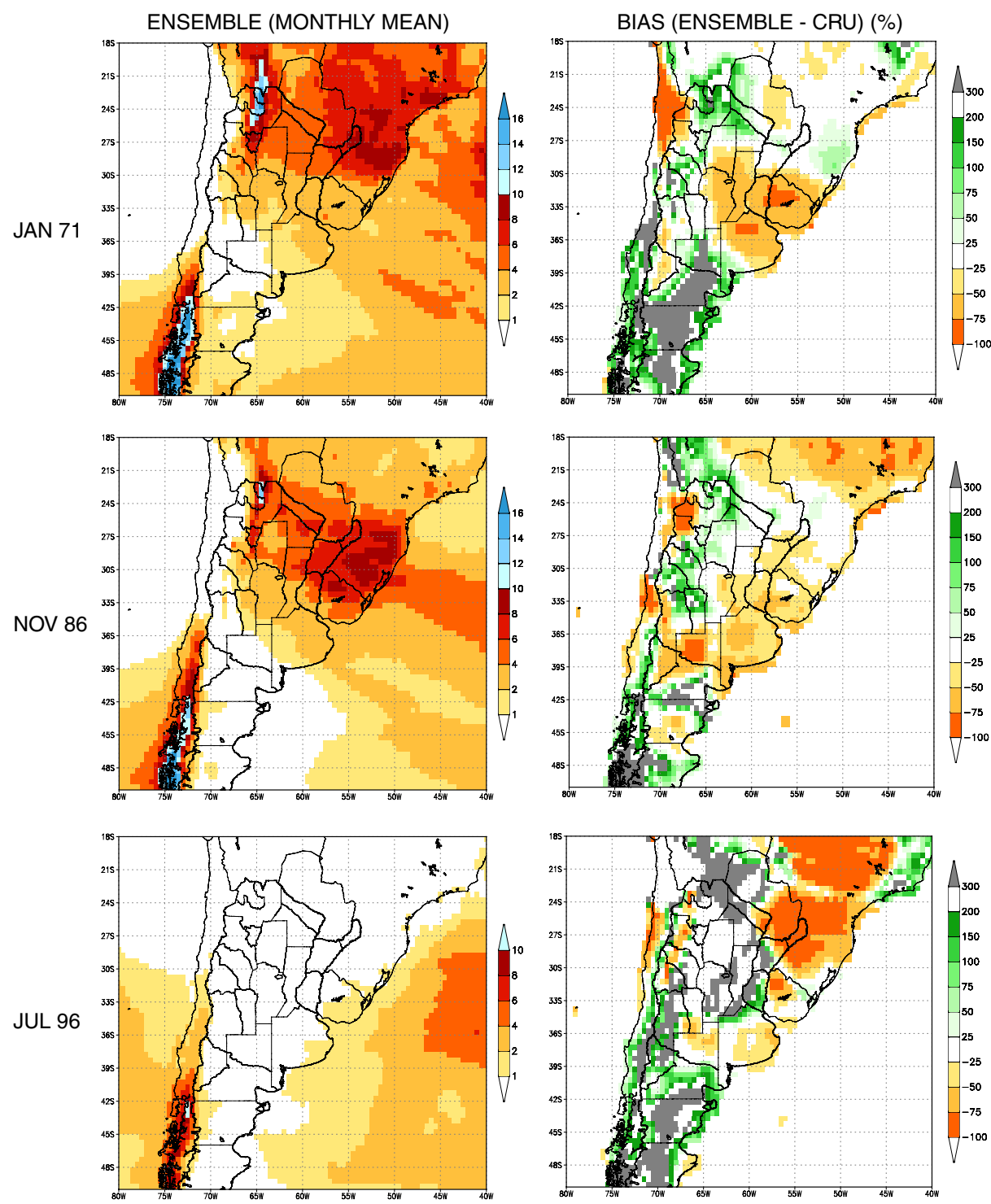

Fig. 6 Monthly mean precipitation for the models ensemble and per cent biases for January 1971, November 1986 and July 1996. Units: millimeter per day

By experimental design, models use comparable resolution as well as the same forcing lateral boundary conditions. Thus the models' spread is influenced by factors specific to the internal model physics and dynamics (i.e. intermodel differences may come from different model formulation and internal variability). In order to assess the uncertainty in simulating precipitation, we calculated the intermodel spread of monthly mean precipitation (Fig. 7, similarly than for temperature results, for each grid point we evaluate the highest value of the ensemble minus the lowest 
Fig. 7 Monthly intermodel spread for precipitation (see text) for January 1971,

November 1986 and July 1996.

Units: millimeter per day
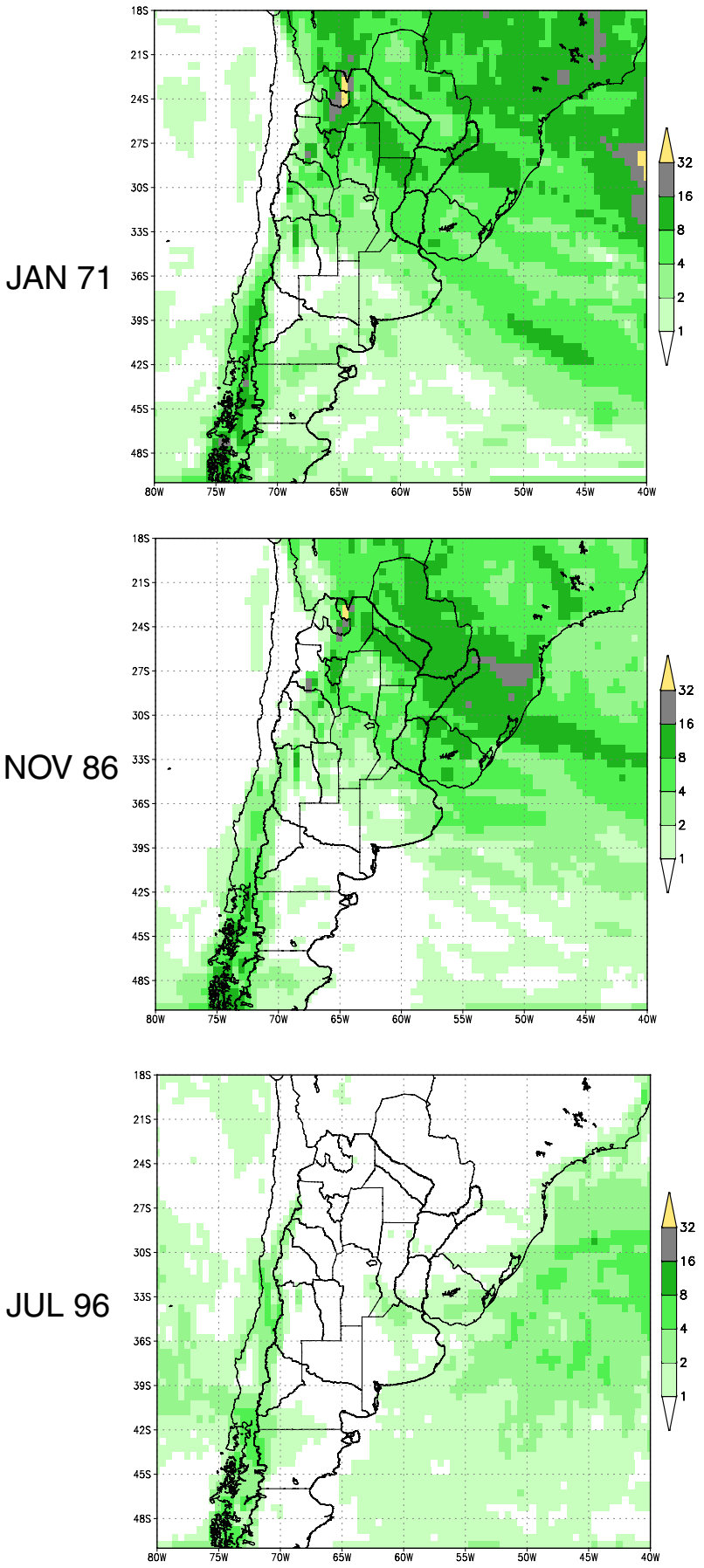

value). For January 1971 and November 1986 the intermodel range of monthly mean precipitation is very large over large areas of south-eastern South America. The area with large intermodel spread is more extended in January 1971 than in November 
1986. The location of the intermodel range maxima coincides approximately with the ensemble monthly mean maxima. Not surprisingly, the agreement between models is better in July 1996 than in the spring and summer months (wintertime weather is dominated by resolved circulation). For comparison, the intermodel spread of monthly precipitation tends to be smaller than the observed interannual spread for each single month in the southern La Plata Basin. In regions of large precipitation (e.g. NEA) both measures are similar.

\subsection{Frequency distribution of the daily rainfall rates}

Despite the biases in precipitation and the large inter model spread in the monthly time-scale, the day-to-day variability tends to be relatively well represented. In general, the models approximately coincide in the timing of dry days and main precipitation events, but they do not coincide in magnitude. The intermodel agreement in the daily variation of wet and dry days is more evident during periods when precipitation is mainly controlled by the large-scale tropospheric forcing (e.g. during winter, see Fig. 8). This suggests that the models are producing the correct simulation of precipitation-generating circulation, but not the correct conversion of water vapour into rain reaching the ground.

A remaining question is the comparison of models' results with daily station data and with the statistical downscaling technique. The targets are twofold: to explore the extent to which using a statistical downscaling technique improves the downscaling of the distribution of precipitation in intensity classes, and to explore how both techniques (dynamical and statistical downscaling) capture the heaviest rainfall days. In order to answer the first issue, we made frequency diagrams of daily precipitation for each model, for the SDS and for the available observational data. For each individual model we count for each grid point in each sub-region (NEA, SME, CEA), the total number of days within each precipitation interval representing dry days or "drizzle" precipitation (0-1 $\mathrm{mm}$ /day) and light (1-5 $\mathrm{mm} /$ day), moderate (5-

Fig. 8 Time series of area mean daily precipitation for all dynamical models for the region CEA. Units: millimeter per day

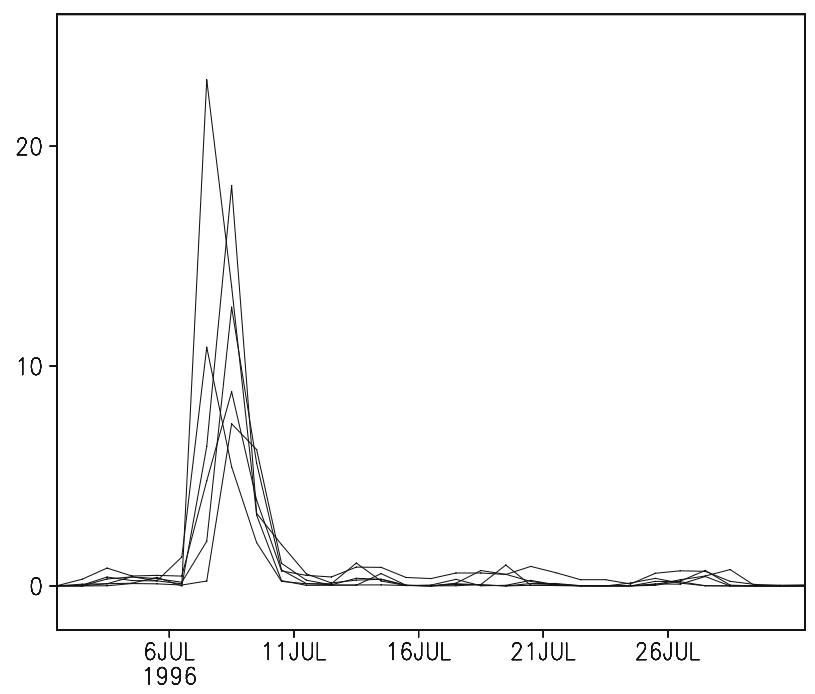


$15 \mathrm{~mm} /$ day), strong (15-30 $\mathrm{mm} /$ day) and heavy (>30 mm/day) precipitation days. Then we evaluate the mean frequency (in percentage) for the considered region during each analyzed period. The results are shown in Figs. 9, 10 and 11, after averaging over models. The frequency distributions for the models are described by the median, the $25 \%$ and $75 \%$, or quartile, values (half of the models lie between these two values) and the maximum and minimum values in the model ensemble. For the SDS and for the in situ data, the methodology is similar but we count for each station the number of days in each precipitation regime (we show the mean frequency for the considered region during each analyzed period).

In general, the frequency distribution of daily rainfall rates according to the SDS follows the overall features of those observed over the three regions and during the three periods (Figs. 9-11). The dynamical models' ensemble also seems to succeed in reproducing the overall observed frequency of daily precipitation for all regions and periods. At least, the observed frequency is often found within the min-max range of the ensemble and is at times found within the inter-quartile range. But we notice that most dynamical models tend to underestimate the frequency of dry days over NEA and overestimate the amount of light rainfall days in the three regions. As expected, the number of events in the higher intensity regimes tends to be under simulated by the models. During the first period (Fig. 9), the SDS always gives a better estimate of the frequency of rainfall in each range of amounts than the models or the mean of the models. However, the differences between observations and SDS estimates in the frequency of heavy precipitation days are quite noticeable. During the second period (Fig. 10), it is striking in NEA that the SDS simulates much better the observation probability of dry days. During the third period (Fig. 11), which was not characterized by heavy rainfalls, the differences between the dynamical and statistical results are low. Overall, and especially during the first and second periods, the statistical model overcomes the dynamical ensemble in representing all ranges of precipitation amounts.
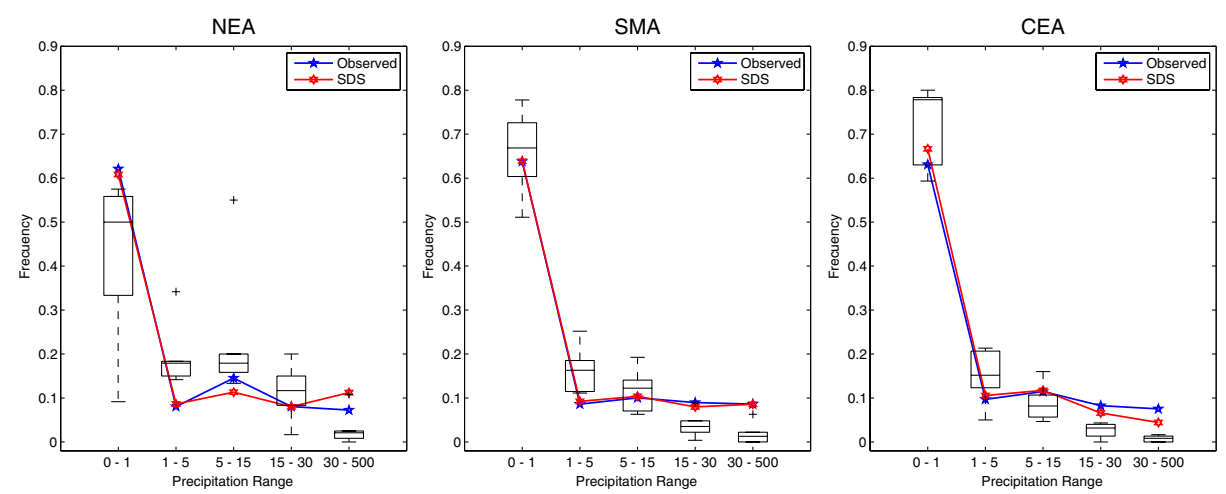

Fig. 9 Intermodel range of frequency of daily precipitation for the regions NEA, SME and CEA for January 1971. For each grid point and each model, we count the total number of days within each precipitation interval. For each interval, the figure shows the minimum, maximum, median and $25 \%$ and $75 \%$ quartile values among the six models. Blue lines represent observations from meteorological stations and the red lines represent the statistical downscaling results 

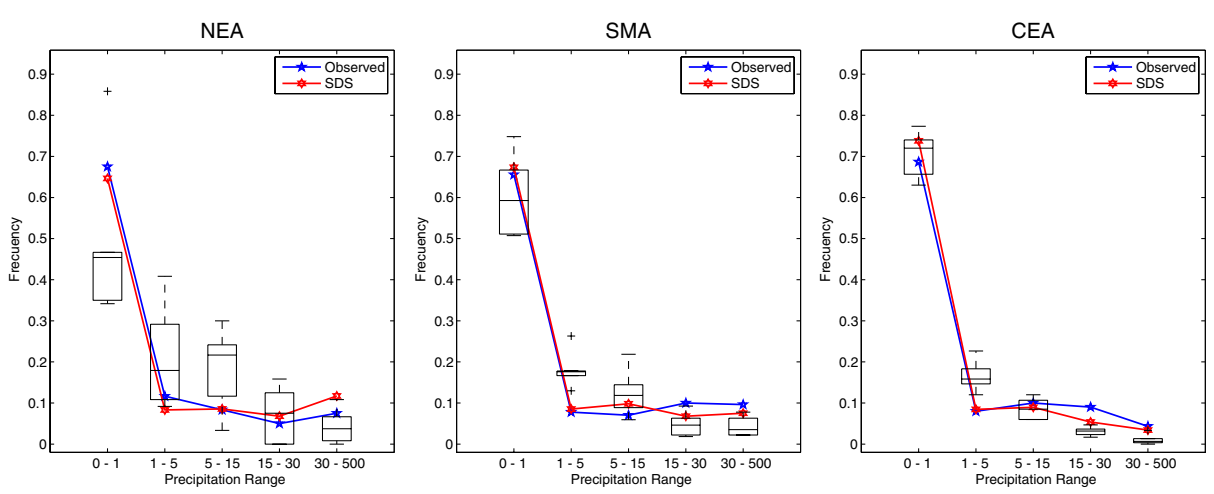

Fig. 10 As Fig. 8, but for November 1986

\subsection{Heavy rainfall}

The rainfall in La Plata Basin has been related in large part to mesoscale convective systems (Velasco and Fritsch 1987; Nesbitt and Zipser 2003). In order to address the simulation of high rainfall extremes associated with intense storms, Fig. 12 shows the 1-day maximum precipitation of the models ensemble at each grid-point for January 1971 and November 1986. This figure helps visualizing how intense a short storm could be in this ensemble. Areas registering intense precipitation in the models ensemble differ between both periods. Peaks of simulated intense rainfall are distributed throughout the SACZ area, southern Brazil and northern Argentina in January 1971, but are more confined in the southern La Plata Basin in November 1986. Heaviest rainfall intensities and locations of maxima also vary substantially between models (not shown). In January 1971, LMDZ, MM5, REMO and PROMES produce peak rainfall exceeding $100 \mathrm{~mm}$ in 24 hours, but only LMDZ and PROMES locate any of such peaks over the southern La Plata Basin, the region of enhanced monthly mean precipitation according to the observed climatology. In November 1986, only REMO produces heavy precipitation with maxima exceeding $100 \mathrm{~mm} /$ day
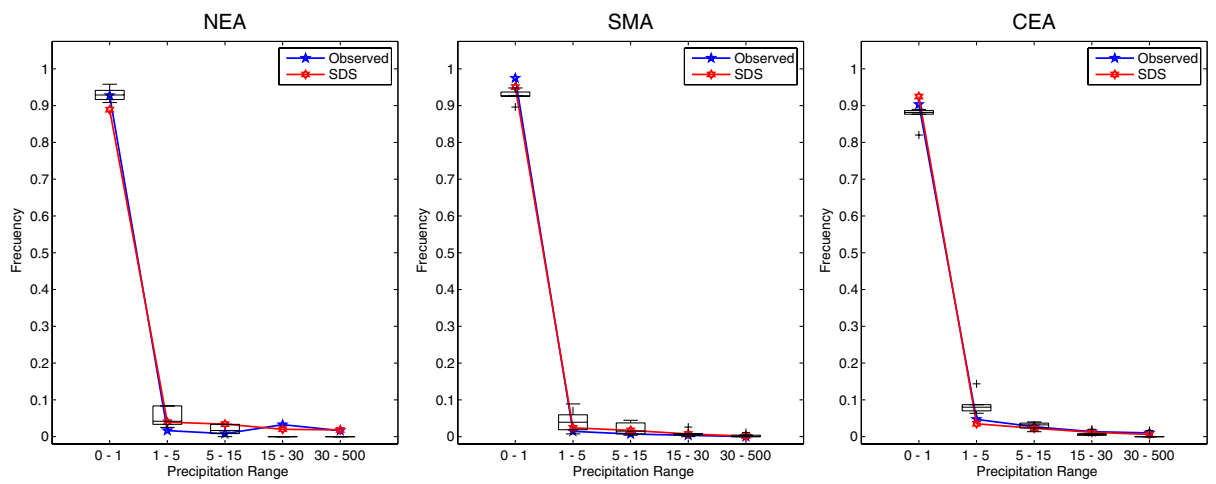

Fig. 11 As Fig. 8, but for July 1996 

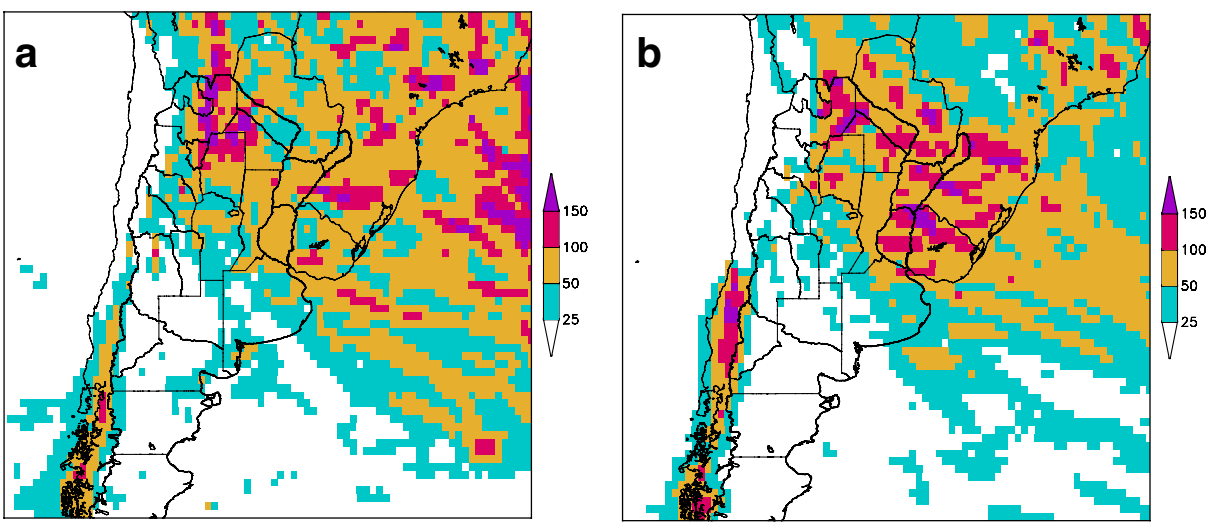

Fig. 12 Heaviest rainfall day (at each grid point we find the heaviest rainfall day in every model, and then we plot the heaviest value of the six models). Units: millimeter per day

over large areas of northern Argentina, Paraguay, southern Brazil and Uruguay. The largest 1-day precipitation amounts produced by the other five models are often in the range $25-100 \mathrm{~mm} /$ day, with larger values in very sparse grid-points. In general, the location of maxima is approximately coincident with the region of anomalously positive mean precipitation for this month (including maxima in central Chile and north western Argentina).

In order to provide a better quantification, Tables 2, 3 and 4. compares the simulated heavy rainfall, as defined by the 1-day monthly maximum precipitation, with corresponding values from the statistical downscaling technique and with station observations. For each sub-region (NEA, CME, CEA), we consider the 1-day monthly maximum precipitation at each station, and then we found the minimum

Table 2 First period (January 1971)

\begin{tabular}{|c|c|c|c|c|c|c|}
\hline \multirow[t]{2}{*}{ Jan 1971} & \multicolumn{2}{|c|}{ NEA } & \multicolumn{2}{|c|}{ SME } & \multicolumn{2}{|l|}{ CEA } \\
\hline & $\overline{\text { Min }}$ & Max & $\overline{\text { Min }}$ & $\operatorname{Max}$ & $\overline{\text { Min }}$ & $\operatorname{Max}$ \\
\hline Observations & 43.6 & 67.4 & 59.9 & 151.6 & 11.3 & 128.1 \\
\hline LMDZ & 11.3 & 27.1 & 9.0 & 66.5 & 11.1 & 53.4 \\
\hline MM5 & 14.8 & 55.2 & 3.9 & 28.2 & 4.2 & 32.6 \\
\hline REMO & 27.7 & 36.6 & 5.9 & 51.8 & 10.1 & 48.6 \\
\hline $\mathrm{RCA}$ & 21.1 & 44.5 & 16.4 & 46.8 & 12.0 & 29.3 \\
\hline PROMES & 36.0 & 49.7 & 34.0 & 84.9 & 6.25 & 48.1 \\
\hline WRF & 22.8 & 37.9 & 10.0 & 29.5 & 5.6 & 26.3 \\
\hline SDS1 & 16.0 & 209.0 & 16.0 & 302.7 & 0.3 & 138.0 \\
\hline SDS2 & 34.5 & 133.6 & 25.7 & 144.0 & 5.7 & 99.0 \\
\hline
\end{tabular}

Range of 1-day monthly maximum precipitation for each sub-region (NEA, SME, CEA) as simulated by each model and from the statistical downscaling method (SDS) and station observations. SDS1 represents the results of the statistical model when computing first the maximum of each simulation of the ensemble at each station, second, the maximum and minimum of these maxima at each station and finally the minimum and maximum among all the stations. SDS2 represents the results of the statistical model when computing first the maximum of each simulation of the ensemble at each station, second, the $90 \%$ and $10 \%$ percentiles of these maxima at each station and finally the minimum and maximum among all the stations. Units: millimeter per day 
Table 3 Same as Table 2 but for the second period (November 1986)

\begin{tabular}{|c|c|c|c|c|c|c|}
\hline \multirow[t]{2}{*}{ Nov 1986} & \multicolumn{2}{|c|}{ NEA } & \multicolumn{2}{|c|}{ SME } & \multicolumn{2}{|c|}{ CEA } \\
\hline & Min & Max & Min & Max & Min & Max \\
\hline Observations & 36.4 & 119.8 & 39.6 & 105.2 & 7.5 & 78.0 \\
\hline LMDZ & 6.3 & 78.6 & 19.1 & 72.3 & 8.6 & 50.0 \\
\hline MM5 & 63.8 & 127.7 & 9.7 & 82.8 & 3.9 & 32.0 \\
\hline REMO & 33.5 & 94.2 & 49.4 & 199.0 & 4.9 & 87.7 \\
\hline $\mathrm{RCA}$ & 17.1 & 37.2 & 16.9 & 66.6 & 6.9 & 42.2 \\
\hline PROMES & 34.9 & 53.9 & 10.1 & 52.1 & 9.8 & 30.7 \\
\hline WRF & 1.1 & 7.2 & 22.5 & 75.8 & 5.2 & 26.1 \\
\hline SDS1 & 18.8 & 209.0 & 12.5 & 315.0 & 4.0 & 225.3 \\
\hline SDS2 & 36.0 & 183.8 & 22.0 & 165.8 & 8.0 & 92.0 \\
\hline
\end{tabular}

and maximum of these quantities. Each min-max interval represents the range of rainfall amounts corresponding to the heaviest rainfall day in the stations of each sub-region for the observations, the models and the statistical downscaling.

Given that the SDS simulation is actually an ensemble of 100 simulations, the methodology to compare SDS and individual dynamical models require some adjustments. Thus, the SDS results are computed in two different ways. For both ways, first the maximum value of each simulation of the ensemble at each station is computed. Second, in the first case, we compute the maximum and minimum values of these maxima at each station, while, in the second case, we compute the $90 \%$ and $10 \%$ percentiles of these maxima at each station. Finally, the minimum and maximum values among all stations are computed and displayed in Tables $2-4$. The second case (selection of $90 \%$ and $10 \%$ percentiles) is considered as the stochastic nature of the SDS ensemble implying that for a large number of simulations, the SDS will simulate all values of the precipitation distribution, although with a probability influenced by the weather patterns observed during the simulated period. Thus, as noted in Tables $2-4$, the range of values computed in the first case always include the observations although these extreme values may have a very low probability of occurrence. When computing the $90 \%$ and $10 \%$ percentiles, the range of values is much similar to the observations although the maximum values are systematically larger than observations. As described in D'Onofrio et al. (2009, this issue), the stochastic nature of the SDS ensembles may require other types of statistical tests in order to evaluate the skill of the SDS to simulate/predict heavy rainfalls. Anyway, given the objective

Table 4 Same as Table 2, but for the third period (July 1996)

\begin{tabular}{|c|c|c|c|c|c|c|}
\hline \multirow[t]{2}{*}{ Jul 1996} & \multicolumn{2}{|c|}{ NEA } & \multicolumn{2}{|c|}{ SME } & \multicolumn{2}{|c|}{ CEA } \\
\hline & Min & Max & Min & Max & Min & Max \\
\hline Observations & 2.0 & 34.0 & 0.0 & 20.0 & 3.0 & 39.0 \\
\hline LMDZ & 1.4 & 6.4 & 2.0 & 23.8 & 3.7 & 25.7 \\
\hline MM5 & 4.4 & 9.8 & 6.7 & 20.6 & 6.3 & 25.7 \\
\hline REMO & 1.3 & 4.2 & 3.7 & 67.5 & 2.7 & 61.6 \\
\hline RCA & 1.0 & 5.0 & 1.7 & 9.9 & 2.6 & 18.7 \\
\hline PROMES & 3.7 & 9.7 & 9.0 & 31.3 & 8.1 & 29.6 \\
\hline WRF & 1.3 & 6.0 & 8.3 & 28.1 & 3.9 & 19.1 \\
\hline SDS1 & 0 & 89.5 & 0.0 & 66.4 & 0 & 95.1 \\
\hline SDS2 & 0.5 & 73.0 & 0.0 & 31.0 & 0.0 & 74.0 \\
\hline
\end{tabular}


of comparison between individual dynamical models, SDS and observations, it can be concluded that the SDS reproduces fairly well the observations.

It is worth noting important remaining methodological issues related to comparing precipitation extremes from station observations with model grid-point values. In particular, care will have to be taken to assess the simulated precipitation extremes against station data because the level of variability in spatially averaged rainfall is not comparable to that of point rain-gauge observations. For example, a model that produces $24-\mathrm{h}$ precipitation events that are as large as found in station data would be somewhat suspect since local intensities measured by rain gauges should be greater than grid box mean intensities simulated by models (even in RCMs running at $50 \mathrm{~km}$ resolution).

\subsection{Moisture transport}

The reasons for the mean biases and errors in the simulation of spatial and temporal variability and extremes in south eastern South America in these particular anomalous months are difficult to assess. To address this problem requires one to understand the consequences of different model formulations at a detailed level. In general, main sources of errors are related to model representation of clouds and cloud feedback, feedbacks between model components, and three-dimensional response to the distribution of atmospheric moisture (Leung et al. 2003). Related possible error sources include a likely excessive decline in soil moisture (and an associated positive feedback of soil moisture drying) and a defective simulation of the regional circulation (particularly the humidity advection from the north).

January 1971 and November 1986 are particularly interesting since these are two cases of monthly extreme precipitation in the region focused by CLARIS. The ensemble and most individual models reproduce the location of the maximum in precipitation near the Rio de la Plata in November 1986 (although with different strength) but not in January 1971. Models tend to be more skilful in that region at simulating November 1986 precipitation likely because the January 1971 climate is more controlled by mesoscale vortices and mesoscale convective complexes, which are harder to simulate. This suggests that models skill is dependent on the strength of the large- and synoptic-scale signature of each period.

Accompanying this anomalous precipitation, an enhanced LLJ transports warm, moist air from the north toward the region, contributing to an increase in the thermal contrast over south eastern South America. The observed and simulated meridional thermal contrast is particularly strong in November 1986. According to Silva and Berbery (2006) this combined patterns of thermal and dynamical variables suggest that large-scale systems, like frontal systems, are important in producing intense rainfall events.

Anomalous high precipitation in south eastern South America is linked with a stronger-than-normal influx of moisture carried by the low level winds. Many recent articles agree on the importance of the low-level flow on the regional precipitation regime (see a recent review in Silva and Berbery 2006). There are two main sources of moisture for the Argentinean plains and La Plata Basin. One of them is related with the LLJ (particularly enhanced during January 1971) while the other is associated with the western branch of the Atlantic anticyclone (predominant during November 1986). This meridional transport of moisture and heat was crucial for the occurrence 
of anomalously high precipitation in southern La Plata Basin during these both periods.

The $850 \mathrm{hPa}$ meridional moisture fluxes at $20^{\circ} \mathrm{S}$ (Fig. 13), is systematically underestimated by all models in January 1971 as compared with the reanalysis, being the spread between models considerably smaller than the difference between the ERA-40 estimate and the ensemble mean around the longitude of the maximum southward flux (around $62^{\circ} \mathrm{W}$ ). In the eastern part of the continent, the scatter grows but the ERA-40 values tend to be within or near the simulated range (i.e. inside the envelope). In November 1986, as expected, the meridional moisture fluxes are better captured by the models. The ensemble mean still underestimates the meridional fluxes of moisture, but the observational estimate is contained by the band of simulated values over a large part of the continent (including the region of

Fig. 13 Eight hundred fifty hectopascals meridional moisture fluxes at $20^{\circ} \mathrm{S}$ from ERA-40 reanalysis and as simulated by the CLARIS models. Shading indicates the range between the largest and smallest of the individual values

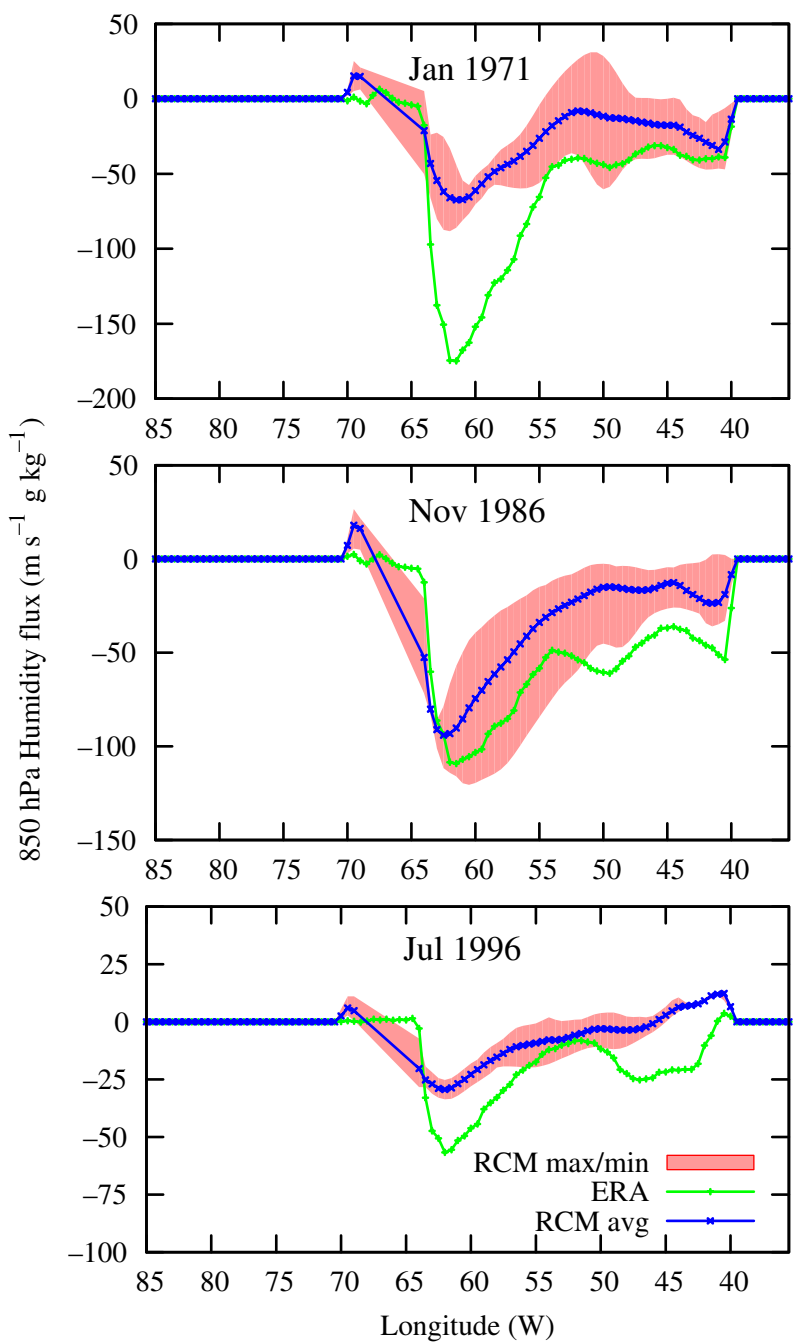


the maximum flux). However, the scatter among the individual models is larger than in January 1971 in the LLJ region. It is worth noting that the LLJ extends over some of the largest data voids in South America and reanalyzes are perhaps not adequate to describe its structure.

\section{Final remarks}

The need for the development of downscaling techniques for South America is increasing in the context of regional integrated assessments and socio-economic applications. This fact motivates a regional modelling intercomparison exercise performed by most of the research centres involved in CLARIS Work Package 3.1. The goal was to assess the capabilities of various RCMs and one stretchedgrid GCM driven by reanalyzes (ERA-40) to simulate particular month-long cases characterized by extreme precipitation conditions in the southern La Plata Basin (January 1971, November 1986 and July 1996). A statistical downscaling method based on weather pattern classification was also tested for downscaling precipitation over that region from ERA-40 (D'Onofrio et al. 2009, this issue) in order to evaluate its performance for specific extreme month-long cases. Overall, and especially during the first and second periods, the statistical model is closer to observations than the dynamical models in representing all ranges of precipitation amounts.

The analysis has emphasized on the simulation of the precipitation over land and has provided a quantification of the biases of and scatter between the different regional simulations. Relatively large biases and intermodel spread are noticed in the simulated rainfall. Most but not all models underpredict precipitation amounts in south eastern South America during the three periods. Results suggest that models have regime dependence, performing better for some conditions than others. In effect, they tend to be more skilful at simulating November 1986 precipitation because the January 1971 climate is more controlled by mesoscale and convective-scale precipitation events. Thermal instability, moist convective activity and the strength of local processes are maximum during summer. These factors add a strong element of randomness and nonlinearity to the models, thereby maximizing the internal model variability and errors, affecting the January 1971 simulation. Wintertime weather is dominated by synoptic scale systems and during the transitional months from winter to summer regimes, precipitation is still relatively controlled by the large-scale tropospheric forcing (i.e. accordingly the models ensemble performs relatively better during November 1986).

CLARIS models tend to underestimate the moisture transport and to misrepresent precipitation, especially in January 1971. These failures in the low-level circulation and in the associated precipitation processes in the LLJ exit region have been previously found in some studies performed with regional models (Vernekar et al. 2003; Paegle et al. 2004). Given the complexity of precipitation processes associated with the LLJ and its interactions with the Chaco low (a thermal continental low over northern Argentina affecting the northerly winds, Seluchi and Marengo 2000) and with transient cyclonic perturbations, perhaps is not surprising that models often fail to capture these features. Simulating the fine-scale precipitation features in south eastern South America remains a troublesome challenge for future research. 
However, we caution that reanalysis does not incorporate satellite observations prior to 1979 and this could negatively influence the lateral boundary conditions over the ocean for the January 1971 case.

A note of caution must be made given the paucity of available in situ data from sites within southern South America. It is necessary to have a better observational network over the region to accurately represent the space-time variability of the regional climate for validating models and developing statistical downscaling techniques. Additionally, our results are based on a small sample (three case studies of 1 month). It is necessary to validate these results from a much larger sample (work in progress).

Simulations were achieved by five regional models and one stretched-grid global model. In addition, a statistical downscaling technique was employed as a complementary method. This first CLARIS downscaling exercise should thus be thought of as typical but not fully comprehensive of the range of possible solutions that stateof-the-art models and downscaling techniques might provide for southern South America. The employed tools are as good as appears possible with the current generation of atmospheric models and statistical techniques, but the uncertainties concerning downscaled precipitation in the region are still significant. Models tend to simulate too dry and warm (cold) conditions during the spring and summer (winter) months. The reasons for the errors in the simulation of precipitation in these particular anomalous periods are difficult to assess, but it seems likely that some physical processes occurring in this region are not efficiently represented in the models. Deficient simulations of the local thermodynamic factors are potentially important for the biases in the present climate and for future changes in the regional climate. For example, feedbacks associated with the drying of the soil in summer would be important and need to be better captured by the models.

This paper represents only a first step in the development of downscaling techniques in the framework of CLARIS and much work still needs to be done to fully test and evaluate models and regionalization tools. More research is also needed to understand the models' capabilities and the variety of simulated feedbacks in the region, and how to combine information from different regional simulations with information from other sources such as statistical downscaling.

Acknowledgements We wish to thank the European Commission 6th Framework programme for funding the CLARIS Project (Project 001454). The three periods were selected by Olga Penalba and Matilde Rusticucci (DCAO, FCEN, Universidad de Buenos Aires) in the framework of CLARIS WP3.2. This work was begun while C.G. Menéndez visited the Facultad de Ciencias del Medio Ambiente in Toledo (Spain), invited by the Universidad de Castilla-La Mancha. The ECOS A04U02 and PIP/CONICET 5416 projects also supported this work. Constructive comments from two anonymous reviewers are greatly appreciated.

Open Access This article is distributed under the terms of the Creative Commons Attribution Noncommercial License which permits any noncommercial use, distribution, and reproduction in any medium, provided the original author(s) and source are credited. 


\section{References}

Barrucand M, Rusticucci M (2001) Climatología de temperaturas extremas en la Argentina. Variabilidad temporal y regional. Meteorológica 26:85-102

Bettolli M, Penalba O, Vargas W (2005) Características de la precipitación diaria en la región sojera Argentina. In: Proceedings of the IX congreso Argentino de meteorología, Buenos Aires

Bony S, Emanuel KA (2001) A parameterization of the cloudiness associated with cumulus convection; evaluation using TOGA-COARE data. J Atmos Sci 58(21):3158-3183

Boulanger J-P, Lafon F, Penalba O, Rusticucci M, Vargas W (2005) Low-frequency modes of observed precipitation variability over the La Plata basin. Clim Dyn 24:393-413. doi:10.1007/ s00382-004-0514-x

Castro M, Fernandez C, Gaertner MA (1993) Description of a meso-scale atmospheric numerical model. In: Diaz JI, Lions JL (eds) Mathematics, climate and environment, Masson (ISBN: 2-22584297-3), p 273

Champeaux JL, Masson V, Chauvin F (2005) ECOCLIMAP: a global database of land surface parameters at $1 \mathrm{~km}$ resolution. Meteorol Appl 12:29-32

Chen F, Dudhia J (2001) Coupling and advanced land surface-hydrology model with the Penn StateNCAR MM5 modeling system. Part I: model implementation and sensitivity. Mon Weather Rev 129:569-585

Christensen OB (1999) Relaxation of soil variables in a regional climate model. Tellus A 51: 674-685

Christensen JH, Hewitson B, Busuioc A, Chen A, Gao X, Held I, Jones R, Kolli RK, Kwon W-T, Laprise R, Rueda VM, Mearns L, Menéndez CG, Räisänen J, Rinke A, Sarr A, Whetton P (2007) Regional climate projections. In: Solomon S, Qin D, Manning M, Chen Z, Marquis M, Averyt KB, Tignor M, Miller HL (eds) Climate change 2007: the physical science basis. Contribution of working group I to the fourth assessment report of the intergovernmental panel on climate change. Cambridge University Press, Cambridge

Cosgrove BA et al (2003) Land surface model spin up behavior in the North American land data assimilation system (NLDAS). J Geophys Res 108:8845. doi:10.1029/2002JD003316

Diaz A, Aceituno P (2003) Atmospheric circulation anomalies during episodes of enhanced and reduced convective cloudiness over Uruguay. J Clim 16:3171-3185

D'Onofrio A, Boulanger J-P, Segura EC (2009) A weather pattern classification system for regional climate downscaling of daily precipitation and temperature. Clim Change. doi:10.1007/s10584-009-9738-4

Ducoudre N, Laval K, Perrier A (1993) SECHIBA, a new set of parameterizations of the hydrologic exchanges at the land-atmosphere interface within the LMD atmospheric general circulation model. J Clim 6:248-273

Dudhia J (1989) Numerical study of convection observed during the winter monsoon experiment using a mesoscale two-dimensional model. J Atmos Sci 46:3077-3107

Dümenil L, Todini E (1992) A rainfall-runoff scheme for use in the Hamburg climate model. In: O'Kane JP (ed) Advances in theoretical hydrology, EGS series of hydrological sciences 1. Elsevier, Amsterdam, pp 129-157

Emanuel KA (1993) A scheme for representing cumulus convection in large-scale models. J Atmos Sci 48:2313-2335

Fuenzalida H (2007) Climate change simulations with PRECIS over Chile. Presentation at the CLARIS final meeting, La Plata, Argentina, June 2007

Garand L (1983) Some improvements and complements to the infrared emissivity algorithm including a parameterization of the absorption in the continuum region. J Atmos Sci 40:230-244

Giorgetta M, Wild M (1995) The water vapour continuum and its representation in ECHAM4, Max Planck institut fuer meteorologie report, vol 162, p 38

Giorgi F, Mearns LO (1999) Introduction to special section: regional climate modeling revisited. J Geophys Res 104:6335-6352

Grell GA, Dévényi D (2002) A generalized approach to parameterizing convection combining ensemble and data assimilation techniques. Geophys Res Lett 29:1693. doi:10.1029/2002GL01531

Hoskins BJ, Hodges KI (2005) New perspectives on the Southern Hemisphere winter storm tracks. J Clim 18:4108-4129 
Hourdin F, Musat I, Bony S, Braconnot P, Codron F, Dufresne J-L, Fairhead L, Filiberti M-A, Friedlingstein P, Grandpeix J-Y, Krinner G, LeVan P, Li Z-X, Lott F (2006) The LMDZ4 general circulation model: climate performance and sensitivity to parametrized physics with emphasis on tropical convection. Clim Dyn 27:787-813

Hsie EY, Anthes RA, Keyser D (1984) Numerical simulation of frontogenesis in a moist atmosphere. J Atmos Sci 41:2581-2594

Jacob D (2001) A note on the simulation of the annual and inter-annual variability of the water budget over the Baltic Sea drainage basin. Met Atmos Phys 77:61-73

Jones CG, Sanchez E (2002) The representation of shallow cumulus convection and associated cloud fields in the Rossby Centre Atmospheric Model. HIRLAM newsletter 41, SMHI, SE-60176 Norrköping, Sweden, pp 91-106

Kain J, Fritsch J (1993) Convective parameterization for mesoscale models: the Kain-Fritsch scheme. In: Emanuell KA, Raymond DJ (eds) The representation of cumulus convection in numerical models. American Meteorological Society, Boston, pp 165-170

Kjellström E, Bärring L, Gollvik S, Hansson U, Jones C, Samuelsson P, Rummukainen M, Ullerstig A, Willén U, Wyser K (2005) A 140-year simulation of European climate with the new version of the Rossby Centre regional atmospheric climate model (RCA3). Reports Meteorology and Climatology No 108, SMHI, SE-60176 Norrköping, Sweden, 54 pp

Kodama YM (1993) Large-scale common features of the subtropical convergence zones (the Baiu frontal zone, the SPZ, and the SACZ). Part II: conditions of the circulations for generating the STCZs. J Meteorol Soc Japan 71:581-610

Krinner G, Viovy N, de-Noblet-Ducoudré N, Ogée J, Polcher J, Friedlingstein P, Ciais P, Sitch S, Prentice C (2005) A dynamic global vegetation model for studies of the coupled atmospherebiosphere system. Glob Chang Biol 19:1015-1048

Leung LR, Mearns LO, Giorgi F, Wilby RL (2003) Regional climate research needs and opportunities. Bull Am Meteorol Soc 84:89-95

Liebmann B, Kiladis GN, Vera CS, Saulo AC, Carvalho LMV (2004) Subseasonal variations of rainfall in South America in the vicinity of the low-level jet east of the Andes and comparison to those in the South Atlantic convergence zone. J Clim 17:3829-3842

Marengo JA (2007) Integrating across spatial and temporal scales in climate projections: challenges for using RCM projections to develop plausible scenarios for future extreme events in South America for vulnerability and impact studies. In: Meeting report (papers) of the IPCC TGICA regional expert meeting, Nadi, Fiji, 20-22 June 2007

Marengo JA, Soares WR, Saulo C, Nicolini M (2004) Climatology of the low-level jet east of the Andes as derived from the NCEP-NCAR reanalyses: characteristics and temporal variability. $\mathrm{J}$ Clim 17:2261-2280

Menéndez CG, Cabré MF, Nuñez MN (2004) Interannual and diurnal variability of January precipitation over subtropical South America simulated by a regional climate model. CLIVAR Exchanges 29:1-3

Menéndez CG, Sörensson AA, Samuelsson P, Willén U, Hansson U (2007) Simulating soilprecipitation feedbacks in South America. In: Meeting report (papers) of the IPCC TGICA regional expert meeting, Nadi, Fiji, 20-22 June 2007

Misra V, Dirmeyer PA, Kirtman BP (2003) Dynamic downscaling of seasonal simulations over South America. J Clim 16:103-117

Mlawer EJ, Taubman SJ, Brown PD, Iacono MJ, Clough SJ (1997) Radiative transfer for inhomogeneous atmospheres: RRTM, a validated correlated-k model for the longwave. J Geophys Res 102D:16663-16682

Morcrette J-J (1991) Radiation and cloud radiative properties in the ECMWF operational weather forecast model. J Geophys Res 96D:9121-9132

Morcrette J-J, Smith L, Fourquart Y (1986) Pressure and temperature dependance of the absorption in longwave radiation parameterizations. Beitr Phys Atmos 59:455-469

Nesbitt SW, Zipser EJ (2003) The diurnal cycle of rainfall and convective intensity to three years of TRMM measurements. J Clim 16:1456-1475

New M, Hulme M, Jones P (1999) Representing twentieth-century space time climate variability. Part I. development of a 1961-1990 mean monthly terrestrial climatology. J Clim 12:829-856

New M, Hulme M, Jones P (2000) Representing twentieth-century space time climate variability. Part II: development of 1901-1996 monthly grids of terrestrial surface climate. J Clim 13:22172238

Nogués-Paegle J, Mo KC (1997) Alternating wet and dry conditions over South America during summer. Mon Weather Rev 125:279-291 
Nordeng TE (1994) Extended versions of the convective parametrization scheme at ECMWF and their impact on the mean and transient activity of the model in the tropics. ECMWF Research Department, Technical memorandum no 206, October 1994. European Centre for Medium Range Weather Forecasts, Reading, UK, pp 41

Núñez M, Solman S, Cabré M (2006) Mean climate and annual cycle in a regional climate change experiment over Southern South America. II: climate change scenarios (2081-2090). In: Proceedings of 8 ICSHMO, 24-28 April 2006. Foz do Iguacu, Brazil, pp 325-331

Paegle J, Ambrizzi T, Berbery H, Campetella C, Garreaud R, Herdies D, Marengo J, Menéndez CG, Nicolini M, Porfirio da Rocha R, Ruiz J, Saulo CS, Seluchi M, Silva Dias PL (2004) Modeling studies related to SALLJEX. CLIVAR Exchanges 29:9-11

Räisänen P, Rummukainen M, Räisänen J (2000) Modification of the HIRLAM radiation scheme for use in the Rossby Centre regional atmospheric climate model. Department of Meteorology, Report No 49, University of Helsinki, pp 71

Rasch PJ, Kristjánsson JE (1998) A comparison of the CCM3 model climate using diagnosed and predicted condensate parameterizations. J Clim 11:1587-1614

Rauscher SA, Seth A, Qian J-H, Camargo SJ (2006) Domain choice in an experimental nested modeling prediction system for South America. Theor Appl Climatol 86:229-246. doi:10.1007/s00704-006-0206-z

Rauscher SA, Seth A, Liebmann B, Qian J-H, Camargo SJ (2007) Regional climate modelsimulated timing and character of seasonal rains in South America. Mon Weather Rev 135:26422657

Rodell M, Houser PR, Berg AA, Famiglietti JS (2005) Evaluation of 10 methods for initializing a land surface model. J Hydrometeorol 6:146-155

Samuelsson P, Gollvik S, Ullerstig A (2006) The land-surface scheme of the Rossby Centre regional atmospheric climate model (RCA3). Report in meteorology 122, SMHI SE-601 76. Norrköping, Sweden

Sass BH, Rontu L, Savijärvi H, Räisänen P (1994) HIRLAM-2 Radiation scheme: documentation and tests. Hirlam technical report no 16, SMHI. SE-601 76 Norrköping, Sweden, 43 pp

Savijärvi H (1990) A fast radiation scheme for mesoscale model and short-range forecast models. J Appl Met 29:437-447

Seluchi ME, Marengo JA (2000) Tropical-midlatitude exchange of air masses during summer and winter in South America: climatic aspects and examples of intense events. Int J Climatol 20:11671190

Seth A, Rauscher SA, Camargo SJ, Qian J-H, Pal JS (2007) RegCM3 regional climatologies for South America using reanalysis and ECHAM global model driving fields. Clim Dyn 28:461-480. doi:10.1007/s00382-006-0191-z

Silva VBS, Berbery EH (2006) Intense rainfall events affecting the La Plata basin. J Hydrometeorol 7:769-787

Solman S, Nuñez M, Cabré MF (2007) Regional climate change experiments over southern South America. I: present climate. Clim Dyn 30:533-552. doi:10.1007/s00382-007-0304-3

Sörensson AA, Menéndez CG, Hansson U, Samuelsson P, Willén U (2007) Present and future climate as simulated by Rossby Centre regional atmosphere model (RCA3) forced by ECHAM5OM over South America. Presentation at the CLARIS final meeting, La Plata, Argentina, June 2007

Stephens GL (1978) Radiation profiles in extended water clouds: II. Parameterization schemes. J Atmos Sci 35:2123-2132

Sundquist H (1978) A parameterization scheme for non-convective condensation including precipitation including prediction of cloud water content. Quart J R Met Soc 104:677-690

Tiedtke M (1989) A comprehensive mass flux scheme for cumulus parameterization in large scale models. Mon Weather Rev 117:1779-1800

Uppala SM et al (2005) The ERA-40 re-analysis. Quart J R Meteorol Soc 131:2961-3012. doi:10.1256/qj.04.176

Velasco I, Fritsch JM (1987) Mesoscale convective complexes in the Americas. J Geophys Res 92(D8):9591-9613

Vernekar AD, Kirtman BP, Fennessy MJ (2003) Low-level jets and their effects on the South American summer climate as simulated by the NCEP ETA model. J Clim 16:297-311 